\title{
Organizational Preparedness for Natural Disasters in Ozamiz City, Philippines
}

\author{
Russel P. Galindo ${ }^{1}$, Grace V. Villanueva ${ }^{2}$, Marie Rosellynn C. Enguito ${ }^{3}$ \\ ${ }^{1}$ Social Sciences Department, College of Arts and Sciences, \\ Misamis University, Ozamiz City, Philippines, \\ ${ }^{2}$ Misamis University Community Extension Program, \\ Misamis University, Ozamiz City, Philippines, \\ ${ }^{3}$ Natural Sciences Department, Misamis University, Ozamiz City, Philippines, \\ Corresponding author: Russel P. Galindo, email: russelpabriga@gmail.com
}

\begin{abstract}
The Philippines is identified as a natural disaster hot-spot and is ranked third among the most disaster risk countries in the world. Typhoons and tropical storms, flood, and earthquakes continue to cause thousands of human deaths and injuries in the country despite efforts of various organizations to intensify strategies for disaster risk reduction. Next to impacts on people, destructions in the critical infrastructure are often the most-compelling concerns in the aftermath of a disaster. This paper looked into the natural disaster preparedness of government and non-government organizations directly responsible for critical infrastructures operation and emergency management functions in Ozamiz City. The area was selected since commercial activities are centered on coastal areas and many of its population are located near the coastal area making it prone to the impacts of hydrological events. This study employed the survey method. Survey questionnaires were administered to 254 administrators and employees from 45 organizations and follow up interviews were conducted. Overall findings revealed that the organizations are moderately prepared for natural disasters. However, findings from the individual category of infrastructure showed that facilities, utilities and transportation organizations are less prepared. Organizations responsible for electrical, fuel, gas, energy, waste and water utilities ranked number one with lowest preparedness level. The findings of this study may help identify vulnerabilities and strategies to improve the resiliency of these critical infrastructures and institutions and may provide the basis to improve local policies pertaining to disaster preparedness.
\end{abstract}

Keywords: emergency, hot-spot, infrastructure, resiliency, vulnerabilities 


\section{Introduction}

Floods, earthquakes, drought, and other natural hazards continue to cause thousands of deaths and injuries, and loss of billions of dollars each year around the world (Kapucu, 2008). For more than 20 years, statistics shows that meteorological and hydrological events have caused the increase in natural disasters (Birkmann \& von Teichman, 2010). An increase in extreme weather conditions has been attributed to global warming (Intergovernmental Panel on Climate Change [IPCC], 2012) which perpetuates climate change (Bovornkitti, 2011). Climate change is sometimes referred to as a hazard or disaster, but it could equally well be viewed as the context within which hazard and disasters arise (Etkin et al., 2012). It causes natural disasters and other adverse consequences of natural calamities (Bovornkitti, 2011).

The Philippines has been ranked third among the most disaster-risk countries in the world (United Nations University Institute of Environment and Human Security [UNU-EHS], 2012), where large percentage of the population resides in disaster-prone areas (Department of Interior and Local Government [DILG], 2012). Dilley et al. (2005) have identified the country as a natural disaster hot-spot. An estimated $50.3 \%$ of its total area and $81.3 \%$ of its population are vulnerable to natural disasters (Dilley et al., 2005). Typhoons and tropical storms are the most common disasters experienced in the country, but incidence of earthquake is also experienced as the country is situated along a highly seismic area (DILG, 2012).

Natural disasters have resulted to destructions in lives, infrastructure, agriculture and properties. In Northern Mindanao, Typhoon "Sendong" in 2011 had resulted to Php1.286 billion estimated worth of damage in infrastructures with Php191.89 million of it in Misamis Occidental (Philippine Information Agency [PIA], 2012). Damages in the roads, bridges and drainage, and flood control were reported. Although Ozamiz City in the southern part of Misamis Occidental was not severely affected, some areas of the city experienced flash floods due to heavy rains (Alipa \& Rosauro, 2012). Damages in properties and agriculture in the neighboring cities and municipalities were also reported. The city may not be located in the typhoon belt, but it is still vulnerable to the effects of climate change. Based on government records, Typhoon "Sendong" 
ranked fourth among the deadliest typhoons to hit the country killing at least 1,080 people (Vila, 2014). The first three were Tropical Storm Thelma ("Uring") in 1991 which killed more than 5,100 people in Ormoc City; Typhoon Bopha ("Pablo") in 2012 which hit the southern island of Mindanao killing about 1,900 people; and Typhoon Ike ("Ruping") which hit the central Philippines in 1984, killing 1,363 people.

The adverse effects of the disaster have motivated different sectors in society to intensify strategies to reduce disaster risk. Mitigation, preparedness, response and recovery are among the phases of disaster risk reduction program of the Department of Interior and Local Government (DILG). In the National Disaster Risk Reduction and Management Plan (NDRRMP) for 2011-2028, which aims towards strengthening the communities to cope and recover from the negative impact of disasters, one of the thematic areas included is disaster preparedness.

According to Austin (2012), disaster preparedness includes actions taken before a disaster that enable social units to respond effectively when disaster strikes. As stressed by Sutton and Tierney (2006), disaster preparedness also encompasses measures in enhancing life safety when a disaster occurs, including the ability to undertake emergency actions to protect property and to engage in rehabilitation and recovery activities.

Activities for disaster preparedness can be evaluated from many different perspectives (Kapucu, 2008). Sutton and Tierney (2006) systematically reviewed preparedness guidance and instruments and identified eight key dimensions of preparedness, which include hazard knowledge; management, direction and coordination; formal and informal response plans and agreements; supportive resources; life safety protection; property protection; emergency coping and key function restoration; and initiation of recovery. From these eight dimensions, Austin (2012) derived seven clusters namely: internal protocol training; external response agreement; disaster response capabilities; information, collection and distribution of staff; client preparation; building protection; and emergency supplies.

These clusters of preparedness activities have to be intensified so that the critical infrastructure that plays an important role in supporting communities can respond against natural disasters to reduce their impacts (Oh, 2010). Disruptions in communication, transportation, water and electric power lines and other infrastructure lifelines that provide critical 
services vital to the emergency response and recovery after a natural disaster can have a debilitating effect on safety, health, economy or a combination thereof. Thus, the ability of a community's infrastructure to perform during and after a severe disturbance can be achieved by enhancing disaster resilience (Frazier et al., 2010) and to realize this, the people behind its operation should be prepared whenever disasters occur.

Organizational preparedness is, therefore, implicitly related to the effectiveness in responding to disasters. Empirical studies are important to understand the paradoxical nature of organizational effectiveness since they further sharpen the analytical connection between preparedness and effectiveness (Banerjee \& Gillespie, 1994). As such, it is deemed important to look into the capacity of the organizations directly responsible for the operations of critical infrastructures that deal with the negative impacts of disasters. This study looked into the capacity of the organizations directly responsible for the critical infrastructures and other groups responsible for emergency management functions that deal with natural disasters in Ozamiz City. The findings may help identify vulnerabilities and strategies to improve the resiliency of these critical infrastructures and institutions and may provide the basis to improve local policies pertaining to disaster preparedness.

\section{Materials and Methods}

This study used the survey method. The modified survey questionnaire (Figure 1) used was developed from the established framework of Austin (2012). After a reliability test was done, the questionnaires were administered to 254 administrators and employees from 45 organizations directly responsible for the critical infrastructures and emergency management functions in Ozamiz City. Deliberate sampling method based on the services provided was employed to examine each of the categories with the following number of respondents: 14 from facilities (residential/barangay); 67 from commercial infrastructure (distribution outlets, hotels and inns, manufacturing companies and offices); 54 from cultural infrastructure (religious institutions and schools); 29 from lifeline infrastructures (food supply, health and communication); 36 from utilities (electrical, fuel/gas/energy, waste and water); 37 from transportation (aviation, ports, bridges, highways and transit); and 23 from emergency 
response groups (law enforcement, fire, social services and voluntary groups). Ozamiz City was selected since commercial activities are centered on coastal areas and many of its population are located near the coastal area making it prone to the impacts of hydrological events. Follow up interviews with some of the respondents were conducted during the retrieval of questionnaires for clarification.

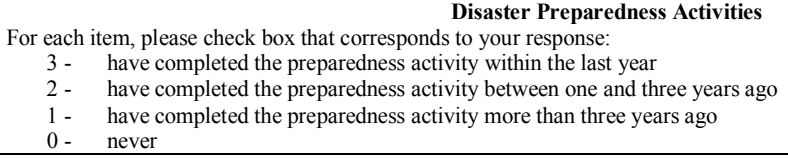
in case of disaster. operational.

E. Client Preparation

F. Building Protection Office. earthquake in the area.

G. Emergency Supplies other disaster.

2. Developed a notification system for staff members/constituents/students and volunteers that can be activated

3. Developed a continuity-of-operation plan in case of disaster - that is, what has to be done to remain

4. Provided life-safety disaster training for staff/constituents/students - that is, training to avoid death or injury should a disaster strike while they are at work.

D. Information Collection and Distribution to Staff

1. Attended meetings or heard talks on how a major earthquake or other disaster would affect the city/area.

2. Obtained educational brochures or printed information from government agencies on how a major earthquake or other disaster would affect the city/area.

3. Obtained information from newspapers, radio, television, the Internet, or other communications media on how a major disaster would affect the city/area.

4. Encouraged staff/constituents/students to develop household disaster plans.

1. Distributed information to clients/constituents on how a major disaster would affect the city/area.

2. Encouraged clients/constituents to develop household disaster plans.

3. Provided training for clients/constituents on how to avoid death or injury should a disaster strike.

1. Had the building(s) inspected by structural engineers or other building professionals from the City Engineers'

2. Sought information on how the building(s) that house your organization could be affected by a major

3. Identified and reduced non-structural hazards in your building (such as bolting furniture to walls, etc.).

1. Obtained first aid supplies for use by organization/barangay in a disaster.

2. Obtained emergency food and water for use by organization/barangay in a disaster.

3. Obtained a generator to provide emergency power in case of electric power outages due to an earthquake or

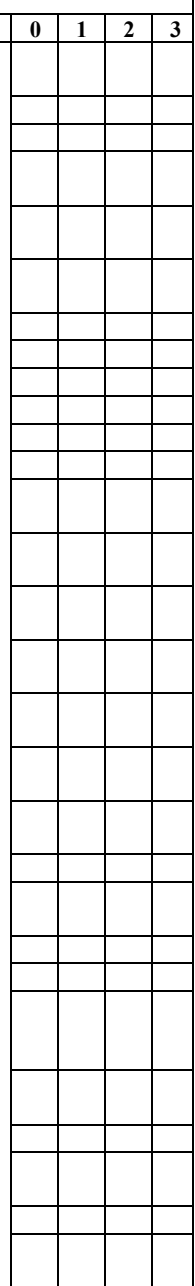

Figure 1. Questionnaire on the disaster preparedness activities. 
The Average Weighted Value (AWV) was computed per item and interpreted per category as follows: $(2.26$ - 3.00) - Well Prepared; (1.51 - 2.25) - Moderately Prepared; $(0.76$ - 1.5) - Less Prepared; $(0-0.75)-$ Not Prepared. The classification of the value was based on the study of Buckle et al. (2000) that showed the continuous practice of the activities could determine organizational preparedness since structures, susceptibility and resources of organizations change over time and performance skills may disappear when not practiced. Perry and Lindell (2003) and International Finance Corporation [IFC] (2010) also showed that disaster preparedness and emergency planning is a continuous and dynamic process.

\section{Results and Discussion}

The survey showed that disaster preparedness of organizations directly responsible for the critical infrastructure and emergency management functions in Ozamiz City varied (Table 1). None of these organizations was well prepared. Organizations for commercial, cultural, lifeline and emergency response were moderately prepared while those responsible for facilities, utilities, and transportation were less prepared.

Table 1. Organizational preparedness for disasters by category of infrastructure/institutions.

\begin{tabular}{cccc}
\hline \hline Infrastructure/Institutions & AWV & Interpretation & Rank \\
\hline Facilities & 1.32 & Less Prepared & 5 \\
Commercial Infrastructure & 1.52 & Moderately Prepared & 4 \\
Cultural Infrastructure & 1.80 & Moderately Prepared & 2 \\
Lifeline Infrastructure & 1.94 & Moderately Prepared & 1 \\
Utilities & 0.76 & Less Prepared & 6 \\
Transportation & 1.50 & Less Prepared & 4 \\
Emergency Response Groups & 1.76 & Moderately Prepared & 3 \\
Overall Average Weighted Value & 1.51 & Moderately Prepared & \\
\hline \hline
\end{tabular}

To determine which of these organizations are the most or the least prepared, they were ranked in terms of the average weighted value. Among the moderately prepared infrastructures, lifeline infrastructure which includes food supply, health, and communication had the highest level of perceived organizational disaster preparedness. In terms of food supply, the National Food Authority (NFA) is the organization responsible 
in ensuring food security in times and places of natural disasters or emergency (National Food Authority [NFA], 2014). Aside from providing the community adequate supply of staple cereals, NFA is mandated to ensure stabilization of the prices of rice in the market especially during natural disasters. Thus, the NFA in Ozamiz City has been ensuring that the populace is provided with the adequate supply of staple food with reasonable retail prices. Food supply in the area is relatively stable at present since the city and other neighboring towns are agricultural areas with hectares of rice fields.

Sustainability of supply in Ozamiz City remains an issue with changes in climate that have resulted to flooding in some rice fields. In China, the food production system has been affected by accelerated temperature warming and associated changes in precipitation and analysis of the interactions of climate change and food production has also been the main focus in their studies ( $\mathrm{Wu}$ et al., 2014). Interview data from this study revealed that in order to become well-prepared during natural disasters, the conduct of trainings and drills on protocols related to food distribution during emergency situations shall be intensified.

In addition to food supply, health services of hospitals in Ozamiz City play a critical role in providing treatment and care to victims in the aftermath of natural disasters. Hospital services are critical in preventing or minimizing the loss of lives during emergencies and disasters hence, when disaster strikes, the society falls back to hospitals to provide immediate relief (United Nations International Strategy for Disaster Reduction [UNISDR], 2010). Equipping the hospitals with the necessary facilities that deal with natural calamities is essential.

The three tertiary hospitals in the City are providing health services under the program of City Health Office (CHO). The program of $\mathrm{CHO}$ includes hospital disaster resilience which ensures that hospitals can respond to natural disasters and maintain their critical functions during emergency situations.

Hospitals are moderately prepared, but respondents from public hospitals stressed during the interview that the government shall allocate a bigger budget for disaster preparedness. Hospitals in Ozamiz City have the specific plan for the disaster management in addition to the general plan, but evaluation of this plan has not been fully executed. Disaster medical care capability, resources, hospital safety, evacuation plan, trainings and 
drills are among the thematic areas included in the plan. As observed, tertiary hospitals have the medical and surgical equipment and staff needed for emergency management but are limited to a particular number of patients. Thus, hospitals could not dispatch a medical rescue team for on-site management.

In terms of disaster resources, emergency medicines and other supplies are available but stocks could not cater tremendous number of patients when disaster happens. Hospitals have emergency generators that can provide automatic back-up source of electricity during emergency situations. With regard to safety, hospitals follow the safety standards but evaluation of these protocols is not maximized. Selected hospital personnel were sent for disaster trainings and attended local coordination meetings pertaining to disaster preparedness. The $\mathrm{CHO}$ suggested that more effort has to be initiated to intensify information dissemination about the protocols that need to be executed before, during and after the onset of a natural disaster.

Communication networks are also vital as they can be utilized to alert the authorities and warn the communities about any forthcoming risks of natural disasters. In Ozamiz City, there are three companies that provide telecommunication services in addition to local radio and television stations. As revealed in this study, these telecommunication companies were equipped with technologies that can inform the public about the current news during emergency situations. Even before the onset of any natural calamity, these communication technologies can help prepare the community by the establishment of networks that can disseminate information about disaster preparedness, monitor any approaching calamity and warn the public particularly those people living in disaster prone-areas. In Bangladesh, an extensive network of radio communication facilities were established at high-risk coastal areas to link with the communication centers (Yodmani \& Hollister, 2001).

The respondents of this study also revealed the need to utilize the telecommunication technologies to enhance the disaster literacy of the public, more importantly on the warning signs and what shall people do when a particular calamity occurs. A study in Indonesia showed the need of the coastal inhabitants of information about the indication when a tsunami is coming and what protocol to follow with its onset (Luik \& Priyowidodo, 2012). 
The telecommunication infrastructure was moderately prepared, and the respondents identified the need to create an emergency committee that should establish a strategic plan for disaster preparedness. This study also revealed that not all staff received the internal protocol training for disaster preparedness, particularly training in communication skills. Haferkamp et al. (2011) stressed the importance of regular communication training among staff members in crisis management units since a fast and accurate line of communication during an emergency situation is indispensable.

The cultural infrastructure which includes the religious institutions and schools ranked second in terms of disaster preparedness as perceived by the respondents. In Ozamiz City, these organizations play a key role in the event of natural disasters. The religious institutions have roles in responding to a disaster, preparing the local communities to become resilient in recovery and aiding the highly-vulnerable families in preventing or reducing potential loss. Recently, a large number of residents in the city were moving hurriedly towards a church for a possible hideaway as the news for the coming of tsunami was spreading all over the place. Despite very late at that night, the church was open, and people stayed until the patrol gave news of a false alarm.

The religious sectors in the city still considered the importance of creating a preparedness committee and the need to raise emergency funds. Improvement in the building structure has to be also intensified. The religious institutions also iterated the importance of making the residents in disaster prone-areas aware of natural calamities and their impact to lives. Outreach programs are among the services that these institutions intend to intensify particularly in the aftermath of the calamity. Wisner (2010) pointed the untapped potentials of the religious communities for disaster reduction in today's time when climate change is accelerated.

Not all schools in the city were active in conducting drills and trainings among the students and personnel. The availability of a medic was also considered in schools. Warning alarms were not available in all schools to signal the occurrence of any natural disaster. Schools also provide the safety and security of their clients during emergency situations, but the rigidity of the guidelines has to be validated. The study of Marincioni and Fraboni (2012) pointed out that a rigid safety protocol 
framework and emergency safety guidelines in universities entail increasing safety leadership, worker's engagement and individual responsibility for safety and security, thereby improving the culture of risk prevention.

Emergency response groups, on the other hand, ranked third among the moderately prepared organizations. These agencies provide protection for the safety and health of the community, as well as the environment in the city. These groups play a very crucial role as they are tasked to respond to any emergency situations. They also educate the people about disaster preparedness for hazards that may impact the city and train them in basic disaster response skills. However, interviews with some respondents revealed that they need adequate equipment to be used during trainings and in the actual response. As front-line responders, they have to be equipped with sufficient tools and facilities for them to function better especially when natural disaster strikes.

Commercial infrastructures in Ozamiz City were also perceived as moderately prepared. As many rely on the services that they cater in the city, they are also expected to be prepared for disasters. Focus on operations, infrastructure, information technology and security may be part of their business activities, but they may not adequately consider the preparedness of the employees who deal with any crisis or disasters. Some of the respondents expressed their need for training and information on disaster preparedness. The employee's role in a disaster is critical since damage from a major disaster may not only include commercial establishments but destruction on homes of employees and infrastructure in the community. Difficulty for the employees to choose between business needs and personal obligations following a major disaster could impact employment responsibilities (Insurance Institute for Business and Home Safety [IIBHS], 2012).

On the other hand, organizations responsible for the facilities, utilities and transportation were perceived to be less prepared for natural disasters. Utilities that include electrical infrastructure, fuel/gas/energy, waste management and water supply have the lowest level of perceived organizational disaster preparedness which is quite alarming. Being the providers of basic services (electricity, water, fuel, waste disposal), they are expected to be more disaster resilient among others. Natural disasters do not only damage homes but may also result to loss of power in 
residences and businesses. Hence, electrical infrastructure network should be prepared for the impact of calamities as they play a major role to restore the normal functioning of a community after disaster strikes.

Disaster waste is also a well-recognized threat to the health, safety and the environment, and can also be a major impediment to post-disaster rescue operations. Safe handling, removal and management of disaster wastes are central issues in disaster response and recovery (United Nations Environment Program and Office for the Coordination of Humanitarian Affairs [UNEP/OCHA], 2011). Thus, organizations responsible for waste management should be prepared for disasters. Drinking water and sewerage systems, on the other hand, are also exposed to natural disasters hence it should be a priority for such services to operate optimally at all times. The main objective of water supply and sewerage companies is to address the needs of the community so that interruptions in drinking water supply, wastewater collection, treatment and disposal are as brief as possible (Pan American Health Organization [PAHO], 2002).

Barangay and residential organizations as categorized under facilities were also perceived as less prepared. As these organizations directly deal with the community and even the households, ample amount of preparedness on their part may have a significant impact on the readiness of every home towards natural calamities. They can provide support and motivate households and even individuals to engage in preparedness undertakings. Levac et al. (2011) stressed that people require sufficient knowledge, motivation and resources to engage in preparedness activities. The study of Kapucu (2008) also emphasized the importance of household preparedness in response to natural disasters since it was found out that even homes with significant experience of adversities could still be complacent.

Furthermore, organizations responsible for the transportation were also less prepared for disasters as perceived by the respondents. The city has an airport, port and an integrated bus and public utility vehicle terminal, which make it possible for the public to travel easily and transport products. Aside from its usual function, transportation is one of a number of support functions to the public safety agency-led response (Connecticut Legal Rights Project, Inc. [CLRP], 2010). Hence, organizations responsible for transportation should be sufficiently prepared for disasters. However, interview data revealed that some 
organizations did not actively implement disaster preparedness programs. Such a condition may put these transportation facilities at risk making them vulnerable to destructions whenever calamities occur. Such situation may pose a great problem as reconstruction time of transportation infrastructure if damaged tends to be slower as compared to other infrastructure.

Effectiveness in responding to disasters can be attributed to organizational preparedness. Austin (2012) emphasized that disaster preparedness results in a more effective response to disasters, better coordination during disasters, and a speedier recovery from a disaster. However, results showed that organizations are perceived to be less prepared to moderately prepared when it comes to natural disasters as reflected in the average weighted values. This condition can be attributed to various factors such as economic and financial constraints, inadequate knowledge and skills, and complacency. Interviews with some administrators revealed that they lack adequate funds to procure the necessary facilities for emergency and calamities for them to be prepared. They are fully aware of the potential risks for such incapacity but they are left with no choice but to bear with what they have on hand and on what they are capable of producing. Respondents from government organizations expressed their need for an additional budget for the trainings and facilities for disaster preparedness, while those from non-government organizations believed that it is the duty of the government to provide them the necessary training.

Inadequate knowledge and skills is also a challenge among these organizations. Some administrators claimed that they did not have sufficient knowledge on implementing disaster preparedness for their organizations. Some disaster preparedness programs were initiated in the past but were not sustained. They were aspiring that there were agencies and institutions that could offer those trainings and provide the guidelines or blueprint for them to be truly prepared. Furthermore, complacency of these organizations was also seen as an important factor. The findings suggest that disaster preparedness is not a priority for these organizations especially that Ozamiz City has not yet experienced a severe natural disaster. Past experiences with calamities may not be so devastating to create vigilance among these organizations. 
Urban infrastructure systems provide critical services to all sectors of the community (Chang \& Chamberlin, 2003). They support industries and communities and also responding against natural disasters to reduce their impacts (Oh, 2010). Disruptions in communication, transportation, water and power lines and other facilities and lifeline infrastructures cause a great crisis during and after disasters. Consequently, a more concerted endeavor towards disaster preparedness should be employed in these organizations as they play an important role in determining a community's disaster resilience (Chang \& Chamberlin, 2003), functioning and survival.

Table 2 shows that respondents from non-government organizations which include private institutions, religious institutions and civic groups perceived higher level of organizational preparedness as compared to government organizations. The findings could be attributed to a more cooperative behavior in part of some non-government organizations than in the government. Patterson et al. (2010) reported that well-functioning community organizations have the trust of their members and possess the moral authority to urge cooperative behavior that the government lacks. The result of this study is in contrast with the findings of Fowler et al. (2007) in which public government employees expressed the highest level of perceived preparedness for coping with a major crisis or disaster while non-government employees expressed the lowest perception of being prepared.

Table 2. Government and non-government organizational preparedness for disasters.

\begin{tabular}{ccccc}
\hline Organization & $\begin{array}{c}\text { No. of } \\
\text { Organizations }\end{array}$ & Percentage & AWV & Interpretation \\
\hline Government & 20 & 44.44 & 1.48 & $\begin{array}{c}\text { Less Prepared } \\
\text { Non-government }\end{array}$ \\
Total & 45 & 55.56 & $1.6 \square$ & - \\
\hline \hline
\end{tabular}

Table 3 shows that the organizations are moderately prepared in relation to the preparedness clusters as indicated by the overall average weighted value. Among the clusters of preparedness activities, it is in the information collection and distribution to staff; client preparation; and emergency supplies that the respondents perceived to have the highest level of preparedness nonetheless still categorized under moderately 
prepared. They were perceived to be less prepared in all other clusters internal protocol training, external response agreements, disaster response capabilities, and building protection, with external response agreements having the lowest value.

Table 3. Organizational preparedness for disasters by clusters of preparedness activities.

\begin{tabular}{cccc}
\hline \hline Clusters of Preparedness Activities & AWV & Interpretation & Rank \\
\hline Internal Protocol Training & 1.50 & Less Prepared & 2 \\
External Response Agreements & 1.40 & Less Prepared & 3 \\
Disaster Response Capabilities & 1.50 & Less prepared & 2 \\
Information Collection and Distribution to Staff & 1.60 & Moderately Prepared & 1 \\
Client Preparation & 1.60 & Moderately Prepared & 1 \\
Building Protection & 1.50 & Less Prepared & 2 \\
Emergency Supplies & 1.60 & Moderately Prepared & 1 \\
& & & \\
Overall Average Weighted Value & 1.53 & Moderately Prepared \\
\hline \hline
\end{tabular}

The concept of preparedness is multi-dimensional and includes elements such as hazard awareness and analysis, formal plans, mutual aid agreements, enduring social and institutional relationships, resource acquisition, training and education, drills and exercises, and methods for institutionalizing lessons learned (Sutton \& Tierney, 2006). The preparedness clusters used in this study represent a grouping of preparedness activities that mirror the way organizations prepare for disasters (Austin, 2012).

The findings of this study suggest that organizations were not adequately prepared for natural disasters especially in terms of the preparedness activities used in this study. Being less prepared in most of the clusters, these organizations may lack support on disaster preparedness efforts. The problem could be brought about by several reasons, which may range from resistance to thinking about disasters, to reluctance to allocate limited resources, and to conflicts among organizations responsible for planning and preparedness activities (Sutton \& Tierney, 2006). Organizational decision makers may also be hesitant and unwilling to allocate resources properly to develop effective disaster management and preparedness plans for their employees (Massey, 2001).

Much effort is still anticipated for these organizations to be adequately prepared for natural disasters. Preparing for disasters requires leadership, training, readiness and exercise support as well as technical 
and financial assistance (Federal Emergency Management Agency [FEMA], 1993). Table 4 shows the respondents' identified needs that they believed organizations should comply to be truly prepared for natural disasters.

Table 4. Respondents' identified organizational needs in preparing for disasters.

\begin{tabular}{ccc}
\hline \hline Identified Needs & Frequency & Percentage \\
\hline Expertise (trainings, drills and additional information) & 22 & 44.89 \\
Additional funds and equipment & 18 & 36.73 \\
Leadership and coordination & 9 & 18.37 \\
& & 100 \\
Total & 49 & 100 \\
\hline \hline
\end{tabular}

The respondents identified some of their preparedness needs which are classified by themes as follows: expertise; additional funds and equipment; and leadership and coordination. Most respondents expressed that they lacked trainings and knowledge on disaster preparedness. Some of them claimed that they do not have adequate knowledge on what is supposed to do when a disaster strikes while they are at work. Few administrators also reported that they need the expertise of other organizations and agencies to guide them in preparing for natural disasters. On the other hand, some respondents from non-government organizations were expecting the government to help and provide them with disaster-related trainings and information. While, some respondents from government organizations expressed that they need additional funds if they are to prepare for disasters. Still others claimed that they need a disaster preparedness committee in their organization, so somebody could take the lead in preparing them for natural disasters and coordinating with them whenever disasters occur.

Findings showed that the organizations are not sufficiently prepared for natural disasters. This condition may put the city to greater risk and vulnerability. Organizations should realize that with the advent of climate change, occurrence of disasters may become inevitable. Climate change may trigger hazards that can result to natural disasters and other adverse consequences (Bovornkitti, 2011). The situation calls for an ample amount of readiness especially among the critical infrastructure. Thus, preparedness requires a clear program and sufficient support in most organizations. 


\section{Conclusion and Recommendations}

The organizations lacked adequate capacity to deal with the adverse effects of natural calamities. This inadequacy can be traced from various factors ranging from lack of funds, inadequate knowledge and skills, and culture of complacency. These factors need to be addressed since they were found to be barriers towards readiness for disasters among the organizations in Ozamiz City.

Organizational decision makers should realize the importance of having disaster preparedness programs in their administrations and should not hesitate to allocate sufficient budgets for its implementation. The need for adequate knowledge and skills to deal with natural disasters poses a challenge to the local emergency management agencies and other crisisrelevant organizations in the city. There might be a need for them to intensify their efforts on disseminating the necessary information and skills to prevent the adverse effects of disasters. As the culture of complacency tends to dominate in most organizations, efforts geared towards disaster preparedness require strong advocacy in order to encourage these organizations particularly those responsible for electrical, fuel, gas, energy, waste and water utilities to make disaster preparedness among their key priorities. For future researches, corresponding observation-based research may be conducted in order to determine the actual physical/structural situation of these critical infrastructures in relation to natural disaster risks and vulnerabilities. Studies in the area should also look into the preparedness of people at the household and neighborhood scale.

\section{Acknowledgment}

The authors are grateful to the Misamis University for funding this study. The Misamis University Research Center is also recognized for the technical support. The administrators and employees of the various organizations involved in this study are also acknowledged. 


\section{Literature Cited}

Alipa, J. S., \& Rosauro, R. (2012, February 10). Floods swamp Ozamiz City, other towns. Inquirer News. Retrieved from http: // newsinfo. inquirer.net / 143383 / floods-swamp-ozamiz-city-other-towns

Austin, D. W. (2012). Preparedness clusters: A research note on the disaster readiness of community-based organizations. Sociological Perspectives, 55(2), 383-393.

Banerjee, M. M., \& Gillespie, D. F. (1994). Linking disaster preparedness and organizational response effectiveness. Journal of Community Practice, 1(3), 129-142.

Birkmann, J., \& von Teichman, K. (2010). Integrating disaster risk reduction and climate change adaptation: Key challenges - scales, knowledge, and norms. Sustainability Science, 5(2), 171-184. doi: http://dx.doi.org/10.1007/s11625-010-0108-y

Bovornkitti, S. (2011). Global warming vs. climate change. Journal of Health Systems Research, (3)3, 320-322.

Buckle, P., Mars, G., \& Smale, S. (2000). New approaches to assessing vulnerability and resilience. Australian Journal of Emergency Management, The, 15(2), 8.

Chang, S. E., \& Chamberlin, C. (2003). Assessing the role of lifeline systems in community disaster resilience. Multidisciplinary Center for Earthquake Engineering Research.

Connecticut Legal Rights Project, Inc. (2010). Emergency preparedness and transportation security. Retrieved from www.mwcog.org > Home > Elements 
Department of Interior and Local Government. (2012). National disaster risk reduction and management plan 2011-2028. Retrieved from www. dilg.gov.ph / PDF_File /.../DILG-Resources-2012116-420ac 59e31.p...

Dilley, M., Chen, R. S., Deichmann, U., Lerner-Lam, A. L., Arnold, M., Agwe, J., Buys, P., Kjevstad, O., Lyon, B., \& Yetman, G. (2005). Natural disaster hotspots: A global risk analysis. Washington, DC: World Bank. Retrieved from http://documents.worldbank.org /curated /en/2005/04/6433734/natural-disaster-hotspots-global-risk -analysis

Etkin, D., Medalye, J., \& Higuchi, K. (2012). Climate warming and natural disaster management: An exploration of the issues. Climatic Change, 112(3-4), 585-599. doi:http://dx.doi.org/10.1007/ s10584-011-0259-6

Federal Emergency Management Agency. (1993). Emergency management guide for business industry. Retrieved from http://www.fema.gov/pdf/business/guide/bizindst.pdf

Fowler, K. L., Kling, N. D., \& Larson, M. D. (2007). Organizational preparedness for coping with a major crisis or disaster. Business \& Society, 46(1), 88-103.

Frazier, A., Arendt, L., Cimellaro, G. P., Reinhorn, A. M., \& Bruneau, M. (2010). A framework for defining and measuring resilience at the community scale: The PEOPLES resilience framework. MCEER.

Haferkamp, N., Kraemer, N. C., Linehan, C., \& Schembri, M. (2011). Training disaster communication by means of serious games in virtual environments. Entertainment Computing, 2(2), 81-88. doi: 10.1016/j.entcom.2010.12.009. 
Insurance Institute for Business and Home Safety. (2012). Work together to get prepared: the human factor. Retrieved from https://www.disastersafety.org/commercial.../work-together-to-getprepared

International Finance Corporation. (2010). Disaster and emergency preparedness: guidance for schools. Retrieved from www.ifc.org/ $\mathrm{wps} / \mathrm{wcm} /$ connect/.../DisERHandbook.pdf? MOD =AJPERES

IPCC. (2012). Managing the risks of extreme events and disasters to advance climate change adaptation. A special report of working groups I and II of the Intergovernmental Panel on Climate Change (C. B. Field, V. Barros, T. F. Stocker, D. Qin, D. J. Dokken, K. L. Ebi, M. D. Mastrandrea, K. J. Mach, G. K. Plattner, S. K. Allen, M. Tignor, \& P. M. Midgley, Eds.). Cambridge, UK and New York, NY, USA: Cambridge University Press.

Kapucu, N. (2008). Culture of preparedness: Household disaster preparedness. Disaster Prevention and Management, 17(4), 526535.

Levac, J., Toal-Sullivan, D., \& O’Sullivan, T. L. (2012). Household emergency preparedness: A literature review. Journal of Community Health, 37(3), 725-733.

Luik, J. E., \& Priyowidodo, G. (2012). Communicating risks and mitigations of tsunami using new media to coastal communities in pacitan, Indonesia. (Unpublished doctoral dissertation). Petra Christian University, Indonesia.

Marincioni, F., \& Fraboni, R. (2012). A baseline assessment of emergency planning and preparedness in Italian universities. Disasters, 36(2), 291-315. doi: 10.1111/j.1467-7717.2011.01259.x

Massey, J. E. (2001). Managing organization legitimacy: Communication strategies. Journal of Business Communication, 38(2), 153-168. 
National Food Authority. (2014). Mission, vision and mandate. Retrieved from http://www.nfa. gov.ph/index.php?id1 $=9 \& \mathrm{id} 2=1 \& \mathrm{id} 3=0$

Oh, E. H. (2010). Impact analysis of natural disasters on critical infrastructure, associated industries, and communities. (Order No. 3444733, Purdue University). ProQuest Dissertations and Theses, 301. Retrieved from http://search.proquest.com/docview/ 8590037 78? accountid=35994. (859003778)

Pan American Health Organization. (2002). Emergencies and disasters in drinking water supply and sewerage systems: Guidelines for effective response. Retrieved from ec.europa.eu/... /PAHO3\%20$\% 20$ Emergencies $\% 20$ and\%20disasters $\% 20 \mathrm{i} . .$.

Patterson, O., Weil, F., \& Patel, K. (2010). The role of community in disaster response: Conceptual models. Population Research and Policy Review, 29(2), 127-141.

Perry, R. W., \& Lindell, M. K. (2003). Preparedness for emergency response: Guidelines for the emergency planning process. Disasters, 27(4), 336-350.

Philippine Information Agency. (2012). Sendong - damaged infrastructure by Rutchie Aguhob. Retrieved from http://news.pia.gov.ph /index.php?article=1451328334007

Sutton, J., \& Tierney, K. (2006). Disaster preparedness: Concepts, guidance, and research. Paper presented at Fritz Institute Assessing Disaster Preparedness Conference, Sebastopol, California: Fritz Institute.

United Nations Environment Program and Office for the Coordination of Humanitarian Affairs. (2011). Disaster waste management guidelines. Retrieved from https: //docs.unocha.org /sites/dms/Documents/DWMG.pdf 
United Nations International Strategy for Disaster Reduction. (2010). Emergency and disaster preparedness for health facilities, guidance notes. Retrieved from www.unisdr-apps.net/.../1MSSH GuideNotes_Hospital-Preparedness_06...

United Nations University Institute of Environment and Human Security. (2012). World risk report 2012. Retrieved from http://www. ehs.unu.edu /file/get/10487.pdf

Vila, A. (2014, July 8). Deadliest typhoons to hit the Philippines. The Philippine Star News. Retrieved from www.philstar.com/newsfeature/.../ deadliest-typhoons-hit-Philippines Cached

Wisner, B. (2010). Untapped potential of the world's religious communities for disaster reduction in an age of accelerated climate change: An epilogue \& prologue. Religion, 40(2), 128-131. doi:10.1016/j.religion.2009.12.006

Wu, W., Verburg, P. H., \& Tang, H. (2014). Climate change and the food production system: Impacts and adaptation in China. Regional Environmental Change, 14(1), 1-5. doi: 10.1007/s10113-0130528-1

Yodmani, S., \& Hollister, D. (2001, May). Disasters and communication technology: Perspectives from Asia. Paper presented at the Second at the Second Tampere Conference on Disaster Communications (Vol. 28, p. 30). 